\title{
Early recognition of hypohidrotic ectodermal dysplasia
}

\author{
Holm Schneider \\ From 5th International Conference on Ectodermal Dysplasia (ED2012) \\ Erlangen, Germany. 1-3 June 2012
}

Hypohidrotic ectodermal dysplasia (HED) is characterized by severe hypohidrosis, hypoplasia of sweat, sebaceous, submucous, meibomian and mammary glands, hypotrichosis, and oligodontia. In early childhood, HED is a life-threatening disorder based on the risks for hyperthermia and pneumonia. Awareness of the hazards related to this rare genetic disease is most helpful in preventing avoidable calamities. Prognosis therefore depends on the time point of diagnosis.

Typical facial features (frontal bossing, sparse eyebrows and eyelashes, wrinkling and hyperpigmentation of the periorbital skin, saddle nose, everted lips, hypoplastic mandible) may allow immediate postnatal recognition of HED, if the disease is known to the family or the doctor. Molecular analysis of one or more of the 4 candidate genes EDA, EDAR, EDARADD and NEMO can then be arranged to make a definitive diagnosis. Infants with HED may also be identified by their inability to sweat. A survey conducted among parents of 100 children with ectodermal dysplasia registered with the German-Swiss-Austrian patient support group revealed that almost all parents had observed episodes of unexplained fever during the first year of life. If infants had to be placed in an incubator after birth, body temperature recording proved to be of utmost importance and often allowed early clinical diagnosis of HED. Furthermore, recent studies of our group confirmed a consistent, quantifiable defect of sweat gland function in male individuals with HED as a disease biomarker. Pilocarpine-induced sweat volume, palmar or plantar sweat duct density and skin conductance before and after stimulation were determined also in newborn infants. Genotype-phenotype correlation was seen across all measurements of sweat gland function, but, surprisingly, not with respect to the number of sweat glands (which

Department of Pediatrics, University Hospital Erlangen, Germany can be determined very soon after birth) and the degree of oligodontia (diagnosable already by prenatal ultrasonography). This is important, since such easily recognizable signs obviously do not allow prediction of the risk of hyperthermia and the associated morbidity and mortality in HED patients.

Published: 25 May 2012

doi:10.1186/1746-160X-8-S1-I2

Cite this article as: Schneider: Early recognition of hypohidrotic ectodermal dysplasia. Head \& Face Medicine 2012 8(Suppl 1):I2.

Submit your next manuscript to BioMed Central and take full advantage of:

- Convenient online submission

- Thorough peer review

- No space constraints or color figure charges

- Immediate publication on acceptance

- Inclusion in PubMed, CAS, Scopus and Google Scholar

- Research which is freely available for redistribution
C 2012 Schneider; licensee BioMed Central Ltd. This is an Open Access article distributed under the terms of the Creative Commons Attribution License (http://creativecommons.org/licenses/by/2.0), which permits unrestricted use, distribution, and reproduction in any medium, provided the original work is properly cited. 